\title{
Kajian Pendidikan Karakter Dalam Cerita Sundara Kanda
}

\author{
Ni Made Wiratini ${ }^{1}$, Ni Komang Sutriyanti², I Gusti Ngurah Sudiana ${ }^{3}$ \\ 123Universitas Hindu Negeri I Gusti Bagus Sugriwa Denpasar \\ 1dema_putu@yahoo.co.id, 2nikomangsutriyanti@gmail.com, \\ 3ngurah_sudiana@ihdn.ac.id
}

DOI : $10.37329 /$ cetta.v3i2.447

\begin{tabular}{l}
\hline Keywords: \\
\hline Character Education; \\
Sundara Kanda \\
Story \\
\hline
\end{tabular}

\begin{abstract}
Hindu teachings contain a lot about character education, morals, ethics and manners. Moral education can be seen in the story of Sundara Kanda, which is a sub of Itihasa in the Ramayana epic that tells the journey of life with various obstacles and tests that must be faced with full fortitude, strength and determination. Every event that occurs in the Sundara Kanda story is a unified narrative unit in resolving the conflict of every event. The setting in this story uses the setting of Mount Mainaka, Alengka Palace, Taman Angsoka, Kiskinda kingdom. The character is Hanuman who becomes a central figure, then there are goddesses Sitā and Ravana. The accompanying figures are Trijata, Wibisana, Anggada, Jembawan, Sugriwa, Laksmana and Rama. Rahwana as the Antagonist, then there are also giants. His mandate is loyalty and determination in carrying out dharma. Character characters contained in the Sundara Kanda story include characterization displayed through the use of the character's name, through the appearance of the character, and characterization through the author's speech. In accordance with the characters contained in Hindu teachings, namely in the book of Bhagawadgita, the characters in the Sundara Kanda story can be grouped into two characters namely daivi sampad and asuri sampad. The values contained in the character of the Sundara Kanda story include religious, honesty, responsibility, tolerance, discipline, and hard work. As a whole, the character's character value is a national character that should be inculcated and developed to the wider community, in order to shape the attitudes and behavior of a person in carrying out the duties and obligations that should be carried out both towards oneself, the family environment, society, nation and state.
\end{abstract}

\begin{tabular}{lll}
\hline Kata Kunci: & Abstrak \\
\cline { 1 - 1 } $\begin{array}{l}\text { Pendidikan } \\
\text { Karakter; Cerita }\end{array}$ & $\begin{array}{l}\text { Ajaran agama Hindu banyak memuat tentang pendidikan } \\
\text { Sundara Kandar, moral, etika dan budi pekerti. Pendidikan moral } \\
\text { dapat dilihat dalam cerita Sundara Kanda, yang merupakan sub } \\
\text { dari Itihasa dalam epos Ramayana yang mengisahkan perjalanan } \\
\text { kehidupan dengan berbagai rintangan dan ujian yang harus }\end{array}$ \\
\cline { 3 - 3 }
\end{tabular}


dihadapinya dengan penuh ketabahan, kekuatan dan keteguhan hati. Setiap peristiwa yang terjadi dalam cerita Sundara Kanda merupakan satu kesatuan naratif yang utuh dalam menyelesaikan konflik dari setiap peristawa yang ada. Setting dalam kisah ini mempergunakan latar tempat gunung Mainaka, Istana Alengka, Taman Angsoka, kerajaan Kiskinda. Tokohnya adalah Hanuman yang menjadi tokoh sentral, kemudian ada dewi Sitā dan Rahwana. Tokoh pendampingnya adalah Trijata, Wibisana, Anggada, Jembawan, Sugriwa, Laksmana dan Rama. Rahwana selaku Tokoh Antagonis kemudian ada juga para raksasa. Amanatnya adalah kesetiaan dan keteguhan hati dalam melaksanakan dharma. Karakter tokoh yang terdapat dalam cerita Sundara Kanda meliputi karakterisasi yang ditampilkan melalui penggunaan nama tokoh, melalui penampilan tokoh, dan karakterisasi melalui tuturan pengarang. Sesuai dengan karakter yang terdapat dalam ajaran Hindu yaitu pada kitab Bhagawadgita, maka karakter tokoh-tokoh yang terdapat dalam cerita Sundara Kanda dapat dikelompokkan menjadi dua yaitu karakter daivi sampad dan asuri sampad. Nilai yang terkandung dalam karakter tokoh cerita Sundara Kanda meliputi religius, kejujuran, tanggung jawab, toleransi, disiplin, dan kerja keras. Secara keseluruhan nilai karakter tokoh tersebut merupakan karakter bangsa yang patut untuk ditanamkan dan dikembangkan kepada masyarakat luas, guna membentuk sikap dan prilaku seseorang dalam melaksanakan tugas dan kewajiban yang seharusnya dilaksanakan baik terhadap diri sendiri, lingkungan keluarga, masyarakat, bangsa dan negara.

\section{Pendahuluan}

Karakter merupakan hal sangat penting dalam dunia pendidikan demi pendewasaan peserta didik. Tokoh-tokoh yang memiliki karakter kuat, dapat menguatkan dunia pendidikan saat ini. Karakter yang kuat dari tokoh-tokoh baik pewayangan maupun masyarakat akan menjadi suri tauladan bagi anak-anak yang nantinya akan sangat berpengaruh pada perkembangan karakter anak itu sendiri. Pendidikan yang berorientasi pada penguatan karakter adalah pendidikan yang memberikan penguatan pada jati diri itu sendiri. Penanaman karakter pada anak-anak akan menguatkan moral dan etika anak didik, sehingga dengan penguatan pendidikan karakter ini nantinya dapat mengubah perilaku, menanamkan kesadaran dan menguatkan moral guna membangun manusia Indonesia seutuhnya, yang cerdas intelektual memiliki moral yang utuh dan kuat secara jasmani. Undang-undang RI No. 20 Tahun 2003 tentang Sistem Pendidikan Nasional bagian kesembilan pasal 30 ayat 2 
menyatakan pendidikan keagamaan berfungsi mempersiapkan peserta didik menjadi anggota masyarakat yang memahami dan mengamalkan nilai-nilai ajaran agamanya dan atau menjadi ahli ilmu agama. Mewujudkan bangsa yang memiliki budhi pekerti yang baik dan bertanggung jawab tidak bisa dipisahkan dari pendidikan agama, karena pendidikan agama memiliki peranan penting bagi masyarakat untuk dapat membentuk suatu kepribadian yang baik dan memiliki spiritual.

Pada hakikatnya pendidikan karakter itu adalah pendidikan ahlak terpuji, yaitu pendidikan yang mengajarkan, membina, membimbing dan melatih agar peserta didiknya memiliki karakter, sikap mental positif dan berahlak terpuji (Darmadi, 2013). Pendidikan karakter bertujuan membangun kepribadian, watak dan budi pekerti yang luhur sebagai modal dasar dalam berkehidupan di tengah-tengah masyarakat, baik sebagai umat beragama, maupun dalam berkehidupan berbangsa dan bernegara. Pendidikan karakter merupakan suatu upaya yang harus melibatkan semua pihak, baik dalam lingkungan rumah tangga atau keluarga, lingkungan sekolah dan masyarakat luas. Keluarga sebagai lingkungan pertama tentu memiliki peran penting dalam membentuk pola prilaku seorang anak, diantaranya melalui komunikasi yang terarah, kasih sayang, perhatian dan penerapan budi pekerti yang efektif dari orang tua kepada anak. Selain orang tua dalam lingkungan keluarga, peran sekolah sebagai wahana dalam mentransfer ilmu pengetahuan turut mempengaruhi tingkat perkembangan budhi pekerti seorang anak. Masyarakat dalam hal ini juga memegang hal peran penting dalam membentuk budhi pekerti dan ahlak mulia anak, yang tergantung dari pergaulan dan pengaruh lingkungan setempat. Oleh karena itu, pentingnya hubungan dan educational networks diantara ketiga komponen diatas memiliki peran yang sangat penting dalam pembentukan karakter peserta didik dan remaja dimasa kini.

Pendidikan karakter merupakan nilai luhur yang mengutamakan kemampuan berpikir, berkata dan berbuat sesuai dengan norma dan aturan yang berlaku. Pembentukan ahklak mulia remaja Hindu dapat dilakukan dengan menyeimbangkan antara kemampuan berpikir dengan perbuatan. Pengetahuan tentang nilai kejujuran, disiplin, ramah-tamah, kasih sayang, penghormatan dan cinta tanah air di era globalisasi ini sudah mulai jauh dari benak remaja. Di sinilah pembinaan karakter pada remaja Hindu memiliki urgensitas yang sangat tinggi dalam membangun moral anak bangsa. Agama Hindu dalam sistem pendidikan klasiknya yang dijalankan secara turun temurun dari garis perguruan yang disebut parampara, sudah melakukan usaha sadar 
penguatan karakter dan jati diri bagi para sisyanya. Orientasi pendidikan dalam susastra Hindu mengarah pada penguatan batin dan daya spiritual yang merupakan dasar pembangunan moral manusia. Tidak mengherankan bila sisya weda pada jaman-jaman purana, memiliki moralitas yang baik, hal ini dapat kita ketahui dari berbagai keterangan dan penjelasan dalam berbagai kitab purana dan itihasa itu sendiri. Dengan demikian sesungguhnya pendidikan karakter merupakan suatu bagian dari proses pendidikan agama yang menitik beratkan pada pembinaan mental spiritual dan perilaku.

Menurut Tanu (2010) upaya peningkatan mutu pendidikan agama Hindu juga diharapkan dapat menaikan harkat dan martabat manusia Indonesia yang berlandaskan pada etika dan budaya bangsa dan untuk mencapai hal itu maka pendidikan agama Hindu harus bersifat adaptif dalam menerima perubahan zaman yang sangat dinamis, dimana arus globalisasi membawa kemajuan teknologi dan informasi yang pesat. Menurut Jallaluddin (2007) menyebutkan pembinaan mental spiritual menjadi sangat penting ketika merosotnya sistem nilai yang ada di masyarakat hindu, termasuk nilai etika, moralitas dan budi pekerti sebagai akibat dari kemajuan dan arus globalisasi yang tidak terkendali. Pembinaan dan pengembangan pendidikan agama Hindu pada masamasa terdahulu, sekarang dan yang akan datang selalu bersumber dari kitab Veda, Purana, Itihasa beserta kitab-kitab tafsirnya dan susastra-sustra lainnya.

Itihasa dijabarkan dalam kebudayaan Bali, diajarkan dan diberikan dari generasi ke generasi sebagai pembelajaran informal. Hal ini ditemukan dalam pendidikan rohani murni, seperti seorang nabe memberikan petuah kepada sisyanya dalam pelaksanaan upacara diksa. Hal ini memberikan pengaruh yang kuat pada pembentukan karakter murid atau sisya tersebut, dan memberikan dampak yang terlihat oleh semua orang. Menurut (Teeuw, 1991) yang dimasksud dengan sastra adalah alat untuk mengajar, buku petunjuk, buku instruksi atau pengajaran. Dari karya sastra inilah dapat mengembangkan kepekaan terhadap lingkungan. Makna kehidupan yang dilukiskan dalam karya sastra, tidak sepenuhnya berupa cerita fiksi, imajinasi dan kreativitas pengarang, melainkan ada fakta kehidupan yang ingin diungkap di dalamnya, baik yang dialami pengarang sendiri ataupun pengalaman orang lain. Membaca sebuah karya sastra, pembaca diajak untuk mampu saling menghargai, menumbuhkan cinta kasih, mengasah bathin, untuk lebih berbudaya dan peka dengan keadaan lingkungan sekitar. Membaca hasil karya sastra, pembaca dapat mempelajari keindahan dalam karya, baik keindahan bahasa maupun keindahan dalam suatu pemikiran serta dapat 
merenungkan pengalaman-pengalaman sang tokoh cerita (S. Srinivasan, 2012). Sehingga pembaca dapat menentukan sikap, menentukan pilihan hidup dan kehidupan yang dicita-citakannya. Kemudian ajaran yang dapat dipetik dalam karya sastra Hindu adalah ajaran etika dan moral yang dituangkan dalam kisah kehidupan sang tokoh cerita yang sesuai dengan ajaran agama. Pembelajaran moral yang baik dari sebuah kisah cerita dapat dipetik dan dijadikan pedoman dalam menjalankan kehidupan ini sehingga dapat mencerminkan karakter diri.

Berbicara masalah pendidikan etika, moral dan karakter yang termuat dalam ajaran agama Hindu. Dapat dilihat antara lain dalam cerita sundara kanda yang merupakan bagian dari Itihasa dalam epos Ramayana, yang mengisahkan tentang penculikan Dewi Sitā oleh Rahwana dan ditahan di dalam taman Angsoka. Disini terdapat pendidikan karakter keteguhan jiwa dan keberanian sang Hanuman dalam proses pencariannya untuk mengetahui keberadaan Dewi Sitā di kerajaan Alengka. Pada bagian ini diuraikan bahwa seorang Hanuman dan juga dewi Sitā yang memegang teguh pada pendirian, kesetiaan dan kejujuran. Setelah dilakukan studi pustaka pada cerita Sundara Kanda, ternyata banyak terdapat point pendidikan karakter didalamnya. Begitu banyaknya nilai-nilai luhur yang terdapat di dalam cerita Sundara Kanda, oleh sebab itu penelitian ini ingin mengungkapkan nilai tersebut agar tidak hanya sebatas cerita semata, melainkan mampu memberikan manfaat dan mengubah serta mengajak remaja Hindu untuk menjadi lebih baik dan mampu membentengi dirinya dari pengaruh negatif dizaman global ini, supaya menjadi remaja Hindu sebagai generasi bangsa yang mempunyai karakter. Berdasarkan uraian latar belakang tersebut, penulis merumuskan suatu masalah yaitu Bagaimana struktur cerita Sundara Kanda?; Bagaimana karakter tokoh yang terdapat dalam cerita Sundara Kanda? dan Nilai apa yang terkandung dalam karakter tokoh cerita Sundara Kanda? Dengan tujuan untuk menemukan nilai-nilai pendidikan karakter yang terdapat dalam cerita Sundara Kanda.

\section{Metode}

Penelitian mengenai Kajian Pendidikan Karakter dalam Cerita Sundara Kanda, merupakan penelitian kualitatif, karena data yang diperoleh dalam penelitian ini tidak didapat melalui prosedur statistik atau dengan cara kuantifikasi lainya. Menurut Moleong (2014) terdapat sejumlah ciri dan penelitian kualitatif yaitu latar belakang ilmiah, manusia sebagai alat (instrumen) metode kualitatif, analisis data secara induktif 
teori dasar, deskriptfif, lebih mementingkan proses dari hasil, adanya batas yang ditentukan oleh fokus, adanya cerita khusus atau keabsahan data, desain yang bersifat sementara, dan hasil peneltian dirundingkan dan disepakati bersama. Penelitian kualitatif berfokus pada fenomena sosial dan pada pemberian suara pada perasaan dan persepsi dari partisipan di bawah studi (Emzir, 2017).

Penelitian yang mengangkat cerita Sundara Kanda menggunakan pendekatan deskriptif kualitatf, yaitu mendeskripsikan fakta-fakta yang terjadi secara alamiah, dengan memberikan perhatian pada cerita Sundara Kanda yang dikaitan dengan pendidikan karakter dan ajaran-ajaran yang ada dalam pendidikan agama Hindu. Penelitian ini diawali dengan pengumpulan data dengan penelusuran dokumen yaitu dengan mengumpulkan berbagai sumber, baik dari lontar-lontar, transkif teks, bukubuku, majalah, makalah, artikel, observasi di lapangan dan selanjutnya dari sumber tersebut dilakukan pencatatan secara cermat. Obyek utama dalam penelitian ini adalah buku cerita Sundara Kanda, yang merupakan bagian dari epos Ramayana, yang didukung dengan sumber-sumber sastra Hindu lainnya seperti kekawin Ramayana I, Bhagavadgita, Manawa Dharma Sastra, dan sastra-sastra lainnya yang terkait dengan penelitian ini. Yang menjadi data primer adalah buku cerita Sundara Kanda itu sendiri. Sumber data sekunder adalah sumber data yang diperoleh dari tangan kedua (Burhan, 2008). Data sekunder adalah data yang diperoleh atau dikumpulkan oleh yang melakukan penelitian dari sumber-sumber yang telah ada, data ini biasanya diperoleh dari perpustakaan atau laporan-laporan penelitian terdahulu. Data sekundernya adalah naskah-naskah, dokumen, buku, jurnal hingga lontar-lontar yang memiliki korelasi serta hubungan dengan cerita Sundara Kanda itu sendiri.

\section{Hasil dan Pembahasan}

\section{Deskripsi Singkat Sundara Kanda}

Cerita Sundara Kanda ini merupakan bagian dari cerita Ramayana yang khusus menceritakan tentang perjalanan Sang Hanoman sebagai seorang utusan yang ditugaskan oleh rajanya Sugriwa untuk menemukan dewi sita. Dalam sundara kanda tersebut dikisahkan dan diceritakan secara mendetail tentang perjalanan Sang Hanoman mulai dari keberangkatannya menuju Alengka, hingga akhirnya ia menemukan Dewi Sita di taman angsoka, dalam kedukaan yang terpisah dari sang suami, dikisahkan pula bagaimana ia menghancurkan taman angsoka sampai akhirnya ia tertangkap dan diberi 
hukuman dengan membakar ekornya, namun yang terjadi selanjutnya malah sebaliknya, bukan ekornya yang terbakar tapi kerajaan alengkalah yang dihanguskan oleh Sang Hanoman. Cerita sundara kanda ini berakhir pada persiapan Sri Rama bersama pasukan kera untuk menyerang kerajaan Alengka. Yang dalam kekawin Ramayana terdapat dalam kekawin Ramayana I sargah VIII-XI.

\section{Karakter Tokoh Dalam Cerita Sundara Kanda}

Minderop (2005) menyatakan dalam menyajikan dan menentukan karakter (watak) para tokoh, pada umumnya pengarang menggunakan dua cara atau metode dalam karyanya. Metode langsung (telling) dan metode tidak langsung (showing). Metode telling mengandalkan pemaparan watak tokoh pada eksposisi dan komentar langsung dari pengarang. Melalui metode ini keikutsertaan atau turut campurnya pengarang dalam menyajikan perwatakan tokoh sangat terasa, sehingga para pembaca memahami dan menghayati perwatakan tokoh berdasarkan paparan pengarang. Metode showing memperlihatkan pengarang menempatkan diri di luar kisahan denngan memberikan kesempatan kepada para tokoh untuk menampilkan perwatakan mereka melalui dialog dan action. Cerita Sundara Kanda ini memadukan kedua metode tersebut. Tokoh-tokoh utama dalam cerita Sundara Kanda diantaranya (1) Hanoman, (2) Dewi Sitā,

(3) Rahwana. Tokoh-tokoh pendamping diantaranya (1) Rama, (2) Laksmana, (3) Sugriwa, (4) Wibisana, (5) Trijata, dan (6) Indrajit. Karakterisasi tokoh yang menggunakan metode langsung mencakup karakterisasi yang ditampilkan melalui penggunaan nama tokoh, melalui penampilan tokoh, dan karakterisasi melalui tuturan pengarang.

\section{a. Tokoh-Tokoh Utama}

\section{1) Hanoman}

Hanoman merupakan tokoh utama dalam cerita Sundara Kanda. Dalam Hanoman dalam Bahasa sanskerta Hanumān atau Hanumat, juga disebut Anoman adalah salah satu dewa dalam kepercayaan agama Hindu. Hanuman adalah putra dewa Bayu sehingga ia juga memiliki nama Bayusutha, Marutsutha. Sebagai putra dewa Bayu ia memikili karakter yang kuat dan tak gentar dalam menghadapi musuh. Sebagai putra dewi Anjani ia juga dipanggil sebagai Anjaneya yang berarti lahir dari Anjani. Hanoman memiliki penampilan sebagai seekor kera dengan tubuh putih, ia dapat berbicara dengan penuh sopan santun layaknya manusia (Scheeler, 1944). Hanoman memiliki 
badan lebih besar dan kuat dibandingkan dengan kera lainnya. Hanuman mengabdi pada kerajaan Kiskinda dengan rajanya Sugriwa dan ia menjadi bhakta sejati dewa Rama dan dewi Sitā. Hanoman ditampilkan sebagai tokoh protagonis utama dalam cerita Sundara Kanda, dikarenakan dari awal sampai cerita, mengarah pada perjalanan sang Hanoman. Dengan melihat karakteristik tokoh Hanoman tersebut, maka ia merupakan tokoh protagonis yang memiliki karakter daiwi sampad, sebagaimana yang disebutkan dalam Bhagavadgita diantaranya suci hati, bijaksana, mengabdi menguasai ilmu pengetahuan, benar, sopan dan berketetapan hati; cekatan, teguh iman, dan budi luhur.

\section{2) Dewi Sitā}

Dewi Sitā merupakan istri dari Sri Rama yang diculik oleh Rahwana dan ditawan di Taman Angsoka. Sitā merupakan inkarnasi dari Laksmi, dewi keberuntungan, sakti dari Dewa Wisnu. Tokoh Sitā dalam cerita Sundara Kanda, Sitā yang di Indonesia sering disebut dengan Sinta memiliki arti kemurnian, kesucian. Kemurnian Hati yang dimiliki dewi Sitā, sehingga Rahwana yang demikian kuat pun menjadi lemah dan tidak sanggup untuk memaksa memperistri. Dewi Sitā ditampilkan dengan karakteristik tokoh protagonis kedua, ia tampil sebagai seorang perempuan yang lemah secara fisik, dengan penampilan fisiknya yang lusuh, namun memiliki ketetapan hati sebagai seorang istri yang tidak bisa dipisahkan dari suaminya (Kishler, 1965)..

Dewi Sitā sebagai tokoh utama kedua dalam cerita Sundara Kanda, bila dikaji melalui jenis karakter yang tertuang dalam kitab Bhagawadgita terkait dengan karakter daiwi dan asuri sampad, sebagai tokoh protagonis maka Sitā memiliki karakter tokoh daivi sampad dengan sifat-sifat yang ditampilkan antaranya lemah lembut, sopan, berketetapan hati, dan budi luhur.

\section{3) Rahwana}

Rawana dilukiskan dengan sepuluh kepala, menunjukkan bahwa ia memiliki pengetahuan dalam weda dan sastra. Karena punya sepuluh kepala ia diberi nama Dasamukha. Rahwana dengan nama dasamukha yang berarti sepuluh kepala, dan dua puluh tangan yang mencermikan watak serakah. Karakteristik yang ditampilkan oleh Rahwana adalah tokoh yang selalu bertentangan dengan Rama. Rahwana merupakan tokoh antagonis, menampilkan kesombongan, keangkuhan dan keserakahan. Rahwana seorang Raja yang agung. Ia menguasai banyak kerajaan dan menguasai pengetahuan weda dan sastra. Rahwana adalah seorang bhakta Siwa. Rahwana yang dituturkan sebagai seorang Raja yang agung, namun ia tidak memiliki karakter yang 
mencerminkan keagungannya. Sebaliknya, karena kekuatan dan kesaktiannya yang dimilikinya justru membuatnya semakin Angkuh, sombong, congkak, ganas, rakus, bengis, angkara murka, dan serakah, merupakan watak yang bersifat asuri sampad. Keangkuhan dan kesombongannya menyebabkan kehancuran bagi kerajaannya, nasehat perdamaian yang disampaikan oleh Hanoman tidak didengarnya dan justru semakin memicu kemarahannya sehingga ia sangat ingin membunuh Hanoman. Namun ia juga tidak ingin mendapatkan celaan dari orang-orang bijaksana, yang akhirnya hanya memberikan hukuman kepada hanoman, yang tanpa disadari bahwa hukuman yang diberikan itu justru sebaliknya menghancurkan kerajaannya sendiri.

\section{b. Tokoh-Tokoh Pendamping}

\section{1) Rama}

Rama adalah putra sulung dari Raja Dasaratha yang adalah Raghuwangsa, sehingga rama juga disebut Raghuputra dan ibu Kausalya di kerajaan Ayodhya. Rama merupakan salah satu Avatāra Viṣnu. Titib (2003) menyatakan bahwa ketika terjadi kehancuran dunia, hukum dilanggar dan kejahatan merajalela di alam semesta ini, Viṣnu akan menjelma ke dunia untuk menyelamatkan umat manusia dalam berbagai wujud dan bentuk. Rama adalah Avatāra Viṣnu yang ke enam, turun kedunia untuk menumpas keangkaramurkaan yang dilakukan oleh Rahwana. Karakteristik Rama ditampilkan sebagai seorang laki-laki yang tampan, lemah lembut, gagah berani, baik hati, berjiwa satria, arif dan bijaksana. Cerita Ramayana yang mengisahkan perjalanan Rama sebagai Avatāra Viṣnu, yang mengalami banyak cobaan hidup. Diculiknya dewi Sitā oleh Rahwana merupakan cobaan yang sangat berat baginya. Rama dalam cerita Sundara Kanda dituturkan sedang dalam kesedihan karena terpisah dari istrinya.

\section{2) Laksmana}

Lakṣmaṇa adalah tokoh protagonis dalam wiracarita Ramayana, putera Raja Dasarata dan merupakan adik tiri dari Rama. Laksmana merupakan putera ketiga Raja Dasarata yang bertahta di kerajaan Kosala, dengan ibukota Ayodhya. Laksmana memiliki hubungan yang sangat dekat terhadap Rama. Mereka bagaikan duet yang tak terpisahkan. Kemanapun Rama pergi Lakșmaṇa selalu setia menemaninya. Karakteristik Lakșmaṇa ditampilkan sebagai kotoh protagonis pendamping seorang laki-laki yang tampan, gagah berani, baik hati, berjiwa satria, arif dan bijaksana. Ia selalu membawa senjata berupa panah. Dalam cerita Sundara Kanda ia menjadi tokoh pendamping, yang dituturkan sebagai seorang adik yang setia mendampingi dan 
berbakti kepada kakaknya, seperti yang tampak pada penggalan cerita berikut: “...Laksamana yang sangat berbakti pada Rama ikut pergi bersama Rama dan kami bertiga meninggalkan Ayoddhya" (Jelantik, 2011).

\section{3) Sugriwa}

Sugriwa adalah seorang raja kera dan merupakan seekor wanara yang sangat sakti. Ia tinggal di Kerajaan Kiskenda bersama kakaknya yang bernama Subali. Ia adalah teman Sri Rama. Dalam cerita Sundara Kanda ia adalah tokoh pendamping dengan karakteristik yang ditampilkan sebagai tokoh protagonis. Sugriwa bersahabat dengan Rama dan membantu Rama dalam pencarian dewi Sitā. Ia mengutus Pasukan kera yang dipimpin oleh Hanoman untuk menemukan keberadaan dewi Sitā, dan berjanji tidak akan kembali sebelum bertemu dengan dewi Sitā. Sugriwa menepati janjinya sebagai seorang sahabat, seperti tertuang dalam penggalan cerita berikut: “...buatlah dirimu seceria kawanku, Rama. Sitha telah ditemukan, aku merasa mereka tidak akan pernah punya keberanian kembali sebelum tugasnya rampung. Pangeran Anggada yang memimpin pasukan tidak akan pernah kembali padaku, aku yakin itu. Dia pasti takut dengan hukuman yang akan aku jatuhkan pada dirinya dan seluruh pasukannya apabila gagal dalam misinya..." (Jelantik, 2011).

\section{4) Wibisana}

Wibisana adik dari Rahwana, seorang keturunan raksasa dengan berwujud manusia. Ia berani menentang kakaknya (Rahwana), ia menampilkan sifat-sifat daiwi sampad, memiliki karakter yang Arif dan bijaksana, ia juga dipanggil Gunawan Wibisana/Arya Wibisana. Sebagai tokoh protagonis Wibisana menasehati Rahwana untuk tidak membunuh utusan. Ia mengingatkan Rahwana akan ajaran Dharma Sastra, ia mampu meyakinkan Rahwana untuk tidak membunuh Hanoman seperti yang tertuang dalam penggalan cerita berikut: “...Rahwana berkata: Wibisana engkau benar. Salah untuk membunuh utusan dari seorang musuh. Aku harus memikirkan hukuman yang lain untuk dirinya...." (Jelantik, 2011).

\section{5) Trijata}

Dewi Sitā ditahan di taman Angsoka oleh Rahwana dengan ditemani oleh Putri sulung Gunawan Wibisana yang sangat cantik bernama Trijata. Dewi Trijata ditampilkan sebagai tokoh protagonis pendamping dengan watak setia, murah hati, baik budi, sabar dan santun. Dalam cerita Sundara Kanda, Trijata berjasa melindungi dewi Sitā dari ancaman para raksasi, seperti terdapat pada penggalan cerita berikut: 
“...ketika para raksasi berdebat untuk membunuh Sitha, seorang raksasi yang baik dan bijaksana bernama Trijata mendatangi mereka dan berkata: tolong jangan berbicara seperti ini. Jika kalian lapar kalian dapat memakanku. Sitha adalah suci dan dia seharusnya tidak dapat disentuh, ..., janganlah berkata kasar pada Sitha, bersikaplah ramah sehingga bila Rama datang untuk mengambil Sitha, dia tidak akan menghukummu karena perlakuanmu yang menyakitkan" (Jelantik, 2011).

\section{6) Indrajit}

Indrajit putra sulung dari Rahwana, ia juga disebut Megananda. Indrajit tampil sebagai tokoh antagonis dengan senjata panah nagapasa. Ia memiliki karakter asuri sampad dengan sifat angkara. Dalam cerita Sundara Kanda Indrajit berhasil menangkap Hanoman dengan senjata nagapasa, seperti yang tertuang dalam penggalan cerita berikut. “...Indrajit mengambil panah dan memohon senjata astra dari dewa Brahma, dan membidikkan Hanoman. Dia menyadari sekarang bahwa tak mungkin membunuh Hanoman dan ia memutuskan untuk mengikat Hanoman dengan senjata astra. Hanoman yang sangat menghormati Brahma, mengijinkan dirinya diikat oleh senjata astra dan jatuh ketanah (Jelantik, 2011).

Karakter tokoh dalam cerita Sundara Kanda dikaji melalui karakteristik penggunaan nama tokoh, penampilan dan penuturan pengarang. sesuai dengan karakter yang terdapat dalam ajaran Hindu yaitu pada kitab Bhagawadgita, maka karakter tokoh-tokoh yang terdapat dalam cerita Sundara Kanda dapat dikelompokkan menjadi dua yaitu karakter daivi sampad dan asuri sampad. Tokoh-tokoh yang memiliki karakter daivi sampad diantaranya (1) Hanoman, (2) Sita, (3) Rama, (4) Laksmana, (5) Sugriwa, (6) Wibisana dan (7) Trijata. Sedangkan tokoh-tokoh yang memiliki karakter asuri sampad adalah Rahwana dan Indrajit.

\section{Nilai yang Terdapat Dalam Karakter Tokoh Cerita Sundara Kanda}

Pendidikan karakter dengan mengacu pada karakter bangsa yang secara simulat mengarah pada pembentukan manusia yang sadar akan jati dirinya, lingkungan, dapat bersikap toleransi, peduli pada sesama dan memiliki keyakinan kuat terhadap Tuhan Yang Maha Esa. Karakter tersebut merupakan modal dasar untuk membangun bagsa yang adi hulung dan memiliki kepribadian (Srinivasan, 2012). Memanusiakan manusia dengan usaha sadar sebagaimana tertuang dalam tujuan pendidikan nasional sangatlah sulit dilakukan. Hal tersebut terjadi karena pendidikan karakter belum benar-benar 
dapat ditanamkan pada setiap anak didik, sehingga masyarakat yang dibangun dari anak-anak didik yang belum tertanam karakter bangsa dengan kuat dan tumbuh menjadi dewasa ini, dapat mengakibatkan bangsa yang juga tidak berkarakter. Beberapa point mengenai nilai karakter yang dijabarkan dalam cerita Sundara Kanda diantaranya (1) Religius, (2) Kejujuran, (3) Tanggung Jawab (4) Toleransi, (5) Disiplin, (6) Kerja keras.

\section{a. Religius}

Religius adalah nilai karakter dalam hubungannya dengan Tuhan. Ia menunjukkan bahwa pikiran, perkataan, dan tindakan seseorang yang diupayakan selalu berdasarkan pada nilai-nilai Ketuhanan dan/atau ajaran agamanya (Mustari, 2014). Menurut Stark dan Glock (1968), ada lima unsur yang dapat mengembangkan manusia menjadi religious. Yaitu, keyakinan agama, ibadat, pengetahuan agama, pengalaman agama, dan konsekwensi dari keempat unsur tersebut (Mustari, 2014). Dalam ajaran agama Hindu, keyakinan beragama disebut dengan sradha dan bhakti. Bakti sang Hanuman kepada Sri Rama membawanya pada keberhasilan dalam melaksanakan tugasnya, sebelum ia memulai perjalanannya ke Alenka, ia memberikan salam dan sembah kepada para dewa terlebih dahulu, seperti disebutkan pada penggalan cerita berikut: "ia memberi salam kepada dewa yang memimpin keempat wilayah Surya, Indra, Vayu, Brahma. Ia kemudian kembali ke timur dan memberi salam kepada bapaknya Vayu. Dengan pikirannya dia memberi salam kepada kedua bersaudara yang gagah berani Rama dan Laksmana, ia kemudian menyembah laut dan sungai." (Jelantik, 2011).

\section{b. Kejujuran}

Jujur dalam Kamus Besar Bahasa (KBBI) berarti lurus hati, tidak berbohong (berkata apa adanya), tidak curang, tulus, dan ikhlas. Jujur adalah perilaku yang didasarkan pada upaya menjadikan dirinya sebagai orang yang selalu dapat dipercaya dalam perkataan, tindakan dan pekerjaan. Nilai karakter kejujuran adalah sikap ataupun perilaku seseorang yang senantiasa dapat menyesuaikan antara apa yang diucapkan dengan apa yang ada di dalam hatinya sehingga seseorang tersebut dapat dipercayai. (Titib, 2003) menyatakan bahwa kejujuran/kebenaran (satyam) merupakan prinsip dasar hidup dan kehidupan. Seseorang yang senantiasa mengikuti kebenaran, maka hidupnya akan selamat, sejahtera, terhindar dari bencana, memperoleh kebijaksanaan dan kemuliaan. Terkait dengan nilai karakter kejujuran ini, dalam cerita Sundara Kanda disebutkan bahwa adanya kesesuaian antara perkataan dan tindakan 
yang dilakukan oleh dewi Sitā, demi menjaga kesetiaannya terhadap Sri Rama. Kesetiaan, kejujuran dan tanggung jawab dalam hidup merupakan hal yang sangat penting, karena dengan satya tersebut kita bisa memperoleh sebuah kepercayaan yang mungkin tidak semua orang memilikinya. Kesetiaan itu muncul bukan dari orang lain, melainkan dari diri kita sendiri. Bentuk kesetiaan, kejujuran dan tanggung jawab ada lima yang disebut panca satya yaitu:

1) Satya Wacana, Satya Wacana adalah setia, jujur, dan benar dalam berkata-kata. Tidak mengucapkan kata-kata yang tidak sopan. Satya Wacana dalam cerita Sundara Kanda, tercermin dari kesetiaan Sang Sugriwa yang menepati janjinya untuk membantu Sri Rama dalam menemukan istrinya.

2) Satya Hredaya, Satya Hredaya adalah setia terhadap kebenaran dan kejujuran kata hati, berpendirian teguh, dan tidak terombang-ambing. Kesetiaan dan keteguhan hati Dewi Sitā terhadap Rama, sehingga Rahwana tidak mampu untuk menaklukkan hati

3) Satya Laksana, Satya Laksana adalah sikap setia dan jujur mengakui serta mempertanggungjawabkan kebenaran dari segala perbuatan yang telah dilakukan. Satya Laksana ini tercermin dalam penggalan cerita saat Hanuman mengambil keputusan untuk menghancurkan taman Angsoka dengan tujuan agar dapat bertemu dengan Rahwana, dan dipertanggungjawabkan segala perbuatannya itu dengan membiarkan dirinya ditangkap dan dihadapkan dalam persidangan.

4) Satya Mitra, Satya Mitra adalah setia dan jujur kepada teman dalam segala hal, serta berusaha untuk mengarahkan segala tindakan atau perbuatan agar selalu berdasarkan kebenaran sesuai dengan ajaran agama.

5) Satya Samaya, Satya Semaya adalah setia dan jujur terhadap janji yang telah diucapkan serta memenuhi segala sesuatu yang ditimbulkan akibat ucapan janji itu. Satya Semaya dalam cerita Sundara Kanda tercermin pada janji yang diucapkan oleh Sang Hanuman, bahwa ia akan kembali jika sudah menemukan dewi Sitā.

\section{c. Tanggung Jawab}

Tanggung jawab akan terkait dengan kewajiban serta karma phala secara bersamaan. Seluruh tindakan harus dipertanggung jawabkan dan seluruh hal yang menjadi tanggung jawab kita, merupakan kewajiban. Kewajiban sendiri harus 
dikerjakan dengan penuh rasa tanggung jawab. Karakter penuh tanggung jawab ini, digambarkan dan disampaikan secara implisit dari setiap tokoh yang ada dalam cerita Sundara Kanda. Konteks tanggungjawab sendiri bukan hanya bertanggungjawab pada diri sendiri, tapi pada orang lain dan tanggungjawab atas tugas yang harus dilakukan. Hanuman sebagai seorang utusan, yang diutus oleh rajanya untuk mencari dewi Sitā dan memiliki rasa tanggung jawab pada dirinya sendiri dalam melaksanakan tugas dan tanggung jawabnya kepada Rama untuk menemukan dewi Sitā. Tanggungjawabnya sebagai seorang utusan disebutkan dalam penggalan berikut:

Huwus ta yāku umangguh,

ri sirang Janaka putri,

nda tan hana ya wanéhan,

anung ayasā yaśangkwa.

Terjemahannya:

Setelah aku berhasil bertemu, dengan beliau dewi Sitā. Sesungguhnya tidak ada yang lain, yang patut ku usahakan agar aku berjasa. (Penerjemah, 1987)

\section{d. Toleransi}

Toleransi adalah suatu sikap atau perilaku manusia yang tidak menyimpang dari aturan, dimana seseorang menghargai atau menghormati setiap tindakan yang orang lain lakukan. Sikap toleransi sangat perlu dikembangkan karena manusia adalah makhluk sosial dan akan menciptakan adanya kerukunan hidup dengan rasa nyaman. Hal ini tersirat dalam cerita Sundara Kanda ketika Hanoman datang menyampaikan pesan dari Rama kepada dewi Sitā melalui sebuah kidung yang dapat memberikan rasa nyaman kepada dewi Sitā, sehingga melalui kidung tersebut mampu meyakinkan dewi Sitā, bahwa Hanoman bukanlah musuhnya.

Sloka-sloka berikut menunjukkan toleransi yang disampaikan oleh Sang Hanuman kepada Rahwana raja Alengka dengan mengajaknya bersahabat dengan Sri Rama dan mengembalikan dewi Sitā ke sisi Sri Rama, agar ia memperoleh keselamatan. Sloka-sloka berikut terdapat dalam kekawin Ramayana I sargah X sloka 15,16 dan 20.

Kwéh pwa ikā lābhā ning amitra,

haywa ta sakrodang hati śānta,

sĕmbahakĕn déwi nira Sìtā,

Sang Raghuputrā was sira harsā.

Artinya: 
Sesungguhnya banyak hasil orang bersahabat. Janganlah marah tenangkan pikiran Tuanku. Serahkan istri beliau, Dewi Sitā. Sang Rama pasti beliau senang. Tim Penterjemah (192-193: 1987)

Sloka di atas menggambarkan bentuk toleransi yang diberikan oleh Sang Hanuman kepada Sang Rahwana dengan maksud memberikan rasa nyaman terhadap Sang Rahwana.

\section{e. Disiplin}

Disiplin adalah tindakan yang menunjukkan perilaku tertib dan patuh pada berbagai ketentuan dan peraturan (Mustari, 2014). Disiplin ini diperlukan dalam rangka menggunakan pemikiran sehat untuk menentukan jalannya tindakan yang terbaik. Disiplin mengarah pada pikiran, perkataan ataupun prilaku kebijaksaan, yang dalam cerita Sundara Kanda dapat dilihat dalam persidangan di Alengka untuk mengadili sang Hanuman. Beberapa nilai kebijaksanaan disampaikan oleh Sang Wibisana saat memberikan nasihat kepada Sang Rahwana agar ia mencabut kembali perintahnya untuk membunuh Sang Hanuman. Wejangan kebijaksanaan yang disampaikan oleh Wibisana kepada Rahwana agar Rahwana berpegang pada ajaran dharma sastra dalam memperlakukan utusan, seperti yang tertuang dalam sloka berikut :

Bhümi nātha Daśawadana,

Sojaringaji ya pituhun,

Dūta tan dadi pinĕjahan,

yadyapin ya wĕgiga tuwi.

Artinya:

“Tuanku, Maharaja Rahwana. Segala isi darma sastra hendaknya diikuti. Utusan tidak boleh dibunuh, walaupun ia berbuat onar. (Penerjemah, 1987)

\section{f. Kerja Keras}

Kerja keras adalah perilaku yang menunjukkan upaya sungguh-sungguh dalam mengatasi berbagai hambatan guna menyelesaikan tugas (belajar/pekerjaan) dengan sebaik-baiknya (Mustari, 2014). Pantang menyerah adalah salah satu tanda dari kerja yang keras, yaitu usaha menyelesaikan kegiatan atau tugas secara optimal. Kerja keras ini ditandai dengan tiga hal diantaranya: (1) menyelesaikan tugas dalam batas waktu yang ditargetkan; (2) menggunakan segala kemampuan/daya untuk mencapai sasaran; (3) berusaha mencari berbagai alternatif pemecahan ketika menemui hambatan. 
Kerja keras yang tersurat dalam cerita Sundara Kanda ini yaitu bagaimana menjadi orang yang berani, tidak mengenal menyerah, kuat, cerdik, dan dapat dipercaya dalam menjalankan tugas dengan penuh tanggung jawab (Sutriyanti, 2016). Sang Hanuman yang menjadi utusan Sang Rama pergi ke Alengka untuk mencari Dewi Sita. Di sana ia ditangkap namun dapat meloloskan diri dan membakar ibukota Alengka. Dalam babak ini yang menjadi tokoh utama tidak lain adalah Hanoman. Sang Hanoman yang taat akan perintah dari Rajanya Sugriwa dan Rama sendiri.

\section{Kesimpulan}

Struktur naratif dalam cerita Sundara Kanda dibangun dengan bentuk prosa liris, dan mempergunakan Bahasa Jawa-Kuna. Cerita Sundara Kanda ini mengkisahkan penugasan Hanuman untuk melakukan pencarian dewi Sitā ke Alengka, dengan tema adalah tentang kepahlawanan dan kesetiaan. Kemudian alur yang dipergunakan adalah jenis alur maju yang menggunakan tipe episode. Setiap peristiwa yang terjadi dalam cerita Sundara Kanda merupakan satu kesatuan naratif yang utuh dalam menyelesaikan konflik dari setiap peristawa yang ada. Setting dalam kisah ini mempergunakan latar tempat gunung Mainaka, Istana Alengka, Taman Angsoka, kerajaan Kiskinda. Tokohnya adalah Hanuman yang menjadi tokoh sentral, kemudian ada dewi Sitā, Trijata, Wibisana, Anggada, Jembawan, Sugriwa, Laksmana dan Rama. Rahwana selaku Tokoh Antagonis kemudian ada juga para raksasa. Amanatnya adalah kesetiaan dan keteguhan hati dalam melaksanakan dharma.

Karakter tokoh yang terdapat dalam cerita Sundara Kanda dibagi dalam dua bagian yaitu tokoh utama dan tokoh pendamping. Karakter para tokoh tersebut dikaji melalui karakteristik penggunaan nama tokoh, penampilan dan penuturan pengarang. Sesuai dengan karakter yang terdapat dalam ajaran Hindu yaitu pada kitab Bhagawadgita, maka karakter tokoh-tokoh yang terdapat dalam cerita Sundara Kanda dapat dikelompokkan menjadi dua yaitu tokoh-tokoh yang memiliki karakter daivi sampad dan asuri sampad. Nilai yang terkandung dalam karakter tokoh cerita Sundara Kanda meliputi nilai karakter (1) Religius, (2) Kejujuran, (3) Tanggung Jawab (4) Toleransi, (5) Disiplin, (6) Kerja keras. 


\section{Daftar Pustaka}

Burhan, B. (2008). Penelitian Kualitatif: Komunikasi, Ekonomi, Kebijakan Publik, dan Ilmu Sosial lainnya. Jakarta: Kencana Prenada Media Group.

Darmadi, S. (2013). Corporate governance disclosure in the annual report: An exploratory study on Indonesian Islamic banks. Humanomics. https:// doi.org/10.1108/08288661311299295

Emzir. (2017). Metodologi penelitian pendidikan kuantitatif \& kualitatif. In Metodologi penelitian pendidikan kuantitatif $\mathcal{E}$ kualitatif.

Jallaluddin, H. (2007). Filsafat Pendidikan Manusia, Filsafat, dan Pendidikan. Jogjakarta: Aruzz. Media Grup

Jelantik, I. B. (2011). Sundara Kanda. Jakarta: PT Grasindo.

Kishler, T. C. (1965). The Ramayana. Thought. https:// doi.org/10.5840/thought196540139

Minderop, A. (2005). Karakteristik Telaah Fiksi. Jakarta: Yayasan Obor Indonesia.

Moleong, L. J. (2014). Metodologi Penelitian Kualitatif Edisi Revisi. Bandung: PT. Remaja Rosdakarya Offset.

Mustari, M. (2014). Nilai Karakter Refleksi Untuk Pendidikan. Jakarta: PT Raja Grafindo Persada.

Penerjemah, T. (1987). Kekawin Ramayana I. Bali: Dinas Pendidikan Dasar Provinsi Bali Dati I.

S. Srinivasan, S. S. (2012). Value Education Concepts as reflected in Sri Sundara Kanda of Srimad Valmiki Ramayana. International Journal of Scientific Research. https://doi.org/10.15373/22778179/ may2013/29

SCHELER, M. (1944). Formalism in Ethics and Non-Formal Ethics of Values: A New Attempt toward The Foundation of an Ethical Personalism. In Journal of the History of Ideas. https:/ / doi.org/10.2307/2707101

Sutriyanti, N. K. (2016). PENINGKATAN MUTU PENDIDIKAN KARAKTER MELALUI PERAN ORANG TUA DALAM KELUARGA. Jurnal Penjaminan Mutu. https:// doi.org/10.25078/jpm.v2i1.57

Tanu, I. K. (2010). Konsep dan Makna Pembelajaran di Era Biobal. Denpasar: Sari Khyangan Indonesia.

Teeuw. (1991). Sastra dan Ilmu Sastra Pengantar Teori Sastra. Jakarta: PT. Girimukti Pasaka. 
Titib, I. M. (2003). Menumbuhkembangkan Pendidikan Budhi Pekerti Pada Anak (Perspektif Agama Hindu). Bandung: Ganeca Exact. 